\title{
Chapter 3 \\ Towards a Public Sector Data Culture: \\ Data as an Individual and Communal \\ Resource in Progressing Democracy
}

\author{
Petter Falk
}

\begin{abstract}
An increased use of data has swept through many policy areas and shaped procedural and substantive policy instruments. Hence, citizens and governments, as both producers and consumers of data, become intertwined in even more complex ways. But the inherent logic of data-driven services and systems sometimes challenges the prerequisites and ideals of liberal democracy. Though a democratically sound data-practice and data-culture is crucial for ensuring a democratic usage of citizens data, discourse tends to overlook these aspects. Drawing on insights from the project Democracy Data, this chapter explores the opportunities and obstacles for establishing democratically oriented public sector data cultures.
\end{abstract}

Keywords Data-culture - Public sector - Democracy • Value-creation • Design • Conceptualization

\subsection{The Balance of a Data-Driven Democracy}

The balance between individual and collective needs and interests being acknowledged and addressed is a liminal factor in the practices of any liberal democracy (Dahl and Shapiro 2015). Be it protection, taxes, rights or liberties_-government and politics is calibrating this equilibrium in order to create value and allocate resources. Digital data, as a potential recourse, is one that both citizens and governments possess. And as the public sector is entering into an era of algorithmic governance-where algorithms, automation and data-driven services constitute a cornerstone in decision making (Doneda and Almeida 2016), that balance needs a new articulation (Keller et al. 2017).

In order to create value for both the citizens and the communal there needs to be some form of integration between the resources of the individual and the resources of the government (Vargo et al. 2017). Digital data as a resource on an individual level can help the individual inform personal decisions, or help a government professional,

P. Falk ( $\varangle)$

Research Institutes of Sweden, Karlstad University, Karlstad, Sweden

e-mail: petter.falk@ ri.se

G. Concilio et al. (eds.), The Data Shake,

PoliMI SpringerBriefs,

https://doi.org/10.1007/978-3-030-63693-7_3 
like a doctor or social worker, to provide sufficient care. At the same time, that very same singular information-point, when aggregated, can be a collective good. It helps inform decision makers as statistics or real-time data. But an extensive use of individual and aggregated data also carries many risks. On an individual level these range from the infringement of personal integrity to direct or indirect discrimination. On an aggregated level; statistical fallacies or false reliance from not accounting for data quality or causality (Loukissas 2019). So, in sharing data as a resource, as with any democratic value-creating process, balance is needed. Though unlikely such perfect balance will be reached as a perpetual state, or for that matter come to fruition, what the conceptualization and reiteration of democracy has taught us is that striving for democracy as an ideal is as close as one can get (Dahl and Shapiro 2015). And as the public sector is becoming more data-driven some argue that governments need to take a technology-assessment approach to digital tools and concepts in the democratic discourse (Poullet 2009; Nemitz 2018). How does technology shape, contribute to- or disrupt the constitution of democracy? In this regard, articulating an understanding of data on both the citizen's and the government's terms is crucial not only to ensure a representative usage of the public's data, but also to foster a sustainable approach to development and innovation suitable for a public sector logic and a democratic agenda.

It has been said that the strangeness of data is it's strength (Loukissas 2019). Unlike monetary value, where one tax-euro can only be spent on one thing, data can be used and reused in perpetuity. And this strangeness, data's ability to be many things in many settings, and be a resource in more than one way, is becoming an imminent part of our ongoing discussion on democratic ideals. This chapter, in the light of this narrative, illustrates how the data-practice and data-culture of public sectors impacts the balance between individual and communal value-creation. It does this specifically from an administrative point of view, looking at both the infrastructure implementation of data-driven systems and services, concentrating on the data produced directly or indirectly by citizens' usage of welfare service. And, drawing from the research- and innovation project Democracy Data (VINNOVA 2018), it proposes a sequence of interwoven tactics intended for policy makers, public sector managers and data-practitioners in public administration for furthering a democratic tenacity in the practice of government data-culture.

\subsection{The Conflicting Logics of Emerging Public Sector Data Cultures}

In theory it's kind of simple. When the citizen interacts with the public sector in a digital interface, either directly or indirectly, it leaves data as a digital footprint. After this spark of data-creation, data rests in datasets or databases, transits between human and non-human agents or is put to use (Nelson et al. 2009). 
However, the use and understanding of data is not bereft of history, norms and hereditary logics (Bates 2017), a circumstance that is especially significant in a democratic framework. Even though computing as a form of practice for processing information in governments has been around since at least the 1930s (Wynn-Williams 1931), the advent of interconnected computer networks lay the groundworks for governmental data practice back in the 1990s (Ho 2002). Nevertheless, it has not been data as an artefact or resource, but the technological implementation and innovation which has been in the limelight of digitalization discourse. In the emerging days of the Internet, it was theorized that technology would enable new visionary forms of digital culture, empowering direct democracy and removing participatory barriers by means of novel technology (Rheingold 1994; Dyson 1997). However, public sector organizations where more inclined to make incremental changes in existing services and operations using these emerging technologies (Norris 2003). Drawing from commercial rationalities on usage and implementation and merging them with governmental undertakings created concepts like e-government, (Layne and Lee 2001) government e-services (West 2004) or e-democracy (Chutimaskul and Funilkul 2004). Concepts like these lay the initial groundworks for a shared understanding of the digital relationship between the individual citizens and the government (Fang 2002). And within this jargon, the citizens wellbeing, access to- and engagement with their government is very much reliant on the capacity of the user to interact accurately with the system at hand (Jaeger and Bertot 2010), meaning that value was created in action, relying on the agency of the citizen. However, if one looks past the front-end interfaces and technical infrastructure and focuses primarily on data, the notion of agency is less articulated. Of course, governments can do a lot of things with data without the citizens' presents or immediate action. But how does this practice fit into the larger purpose of the public sector?

Given this question, and as more professions, practices, and decision making processes revolved around digital data, and as Big Data moved from viable concept to reality, the term data-culture emerged as a ductile concept (Bates 2017). Behaviours, norms, institutions and knowledge dictating data-practice in a given context are factors that in turn order the prerequisites and ambitions under which data is accumulated, processed and decimated (Kitchin 2015). As any given culture, the dialectic nature between cultivation and organic growth shapes its assemblages, rationalities and realities. The socio-material context and surrounding shape the subject, and it also shapes the understanding of the subject. But directed efforts allow for a group or network to foster or shape their practices through both social and technical factors. As such, local data cultures are created, sustained and transformed by existing in a given environment and the same time interacting with adjacent digital and social systems. This is what constitutes them (Bates 2017). There is of course no universal public sector data culture. As with all institutions, politics and government included, norms and beliefs that dictate social codes are multi-layered arrangements where different local cultures share similarities but also display differences (Hall and Taylor 1996). As such, data-cultures have emerged within the modern-day government, both on national and local levels. These cultures are constituted by the socio-material conditions and practices of digital tools and services that generated and accumulated user- 
and meta-data through a multitude of digital interactions throughout the public sectors digital dispositif. And within the context of any government, such as the local ones, a multitude of data cultures, with unique expressions, norms and practices, can be observed (Bates 2017). There are however, arguably, traits and logics that-from the vantage point of liberal democratic welfare states - are recurrent in most cultures. One such central theme is goal of value-creation for the citizens, a topic that in a digital framing has been covered extensively (Grimsley and Meehan 2007; Ebbers 2016; Nielsen and Persson 2017; Lindgren et al. 2019). In order to create value for its citizens, the democratic government enacts certain arrangements and ideals, such as digital participation, transparency and accountability, improving e-services and using technology to reduce public spending (Jaeger 2005). Another shared trait, if not by all then by the most progressive public sector organizations, is the ambition to hold the competence to understand the data-driven process, or what's commonly called data-literacy (Markham 2020).

What these shared traits of public sector data-cultures illustrate is a need to conceptualize how democratic value is created in a data-driven public sector. But in this conceptualization process there is an inherent and probable prospect of conflicting logics influencing perceptions and foci. In general, we want to assume that the public sector has the ambition to create value for its citizens on democratic basis (Dahl and Shapiro 2015). And even though governments might have been able to do this in a direct way relying on the agency of its citizens, there are norms and hereditary logics in data praxis and digital ventures that can be in conflict with the organizations democratic ambition when it comes to data practice. As much of the practice and culture of data is influenced by the commercial backdrop from which the technologies, languages and enactments of digital discourse has emerged, technology in the public sector is destined to be immersed in commercial logics. This becomes paradoxical in a public sector setting, for example if applying a commercial digital logic to a public welfare service. For example, if commercial data-centric services like Facebook, Google and TikTock using non-linear business models, can create commercial value from user-data, a conventional question would be if public services could create social value using similar data-driven positions, practices and logic? But are such assumptions of public value even apt? Services in a commercial logic is steeped in assumptions from commercial actors, framing the service as situated in a functioning market and as a neutral or positive pursuit. But many governmental services are inherently negative, meaning that services such social welfare and health care generally are service deemed for those in need (Morgan and Rao 2003). Parallel with this, contemporary mainstream data-driven technology is, as mentioned, inherently interconnected with a commercial logic. Systems are developed and procured from commercial agents and the discourse and zeitgeist has, in many ways, been shaped by the companies and innovators who develop the systems. This not only affects how things are done, it also shapes how we understand realities. As the practices of data reflect the ontological positions of its practitioners, discourses and socio-material context inherently also affects ethical and conceptual positions (Bates 2017). Thought research acknowledges the importance of data-literacy in public sector value-creation in order to uphold certain acknowledged democratic principles (Markham 2020), the 
question of how to foster a culture that approaches the multiplicity of data as both an individual and communal recourse, honouring and furthering democratic discourse, is far removed from the contemporary practice and setting of data.

\subsection{The Project Democracy Data-Lessons on Cultivating Local Data Culture from the Swedish Social Services}

The project Democracy Data was initiated in the fall of 2018 to explore the practices, understandings and cultures of data in the social welfare offices of two Swedish cities; Malmö and Karlstad. The project followed and monitored the implementation and iteration of a series of data-driven services and systems throughout a time span of 15 months. Through a mix of para-ethnographic methods, interviews and surveys the project looked at the socio-material context of resources, technology, policy, economy and history constituting local data culture within the municipal social services.

There are a few things to be said about the municipal social welfare administrations in Sweden. In many ways this administrative branch represents the ultimate government safety net in a community. Social work carries a culture of social pathos, stemming from the fact that social work is very much a form of affective practice within a government setting (Penz and Sauer 2019). However, social welfare services in Sweden in general have no map for understanding how, when and where data should and could be used to create social value, beyond the use of mere statistics. Literacy in their data-practice, the project found, is limited, meaning that the complexity of the data-driven systems used on a day-to-day basis (such as electronic records) are often acknowledged, but few have the knowledge or mandate to explore them beyond interface level. Previous research has pointed out that the epistemology in the intersection between the citizens and services, a milieu that very much illustrates social welfare services, often ignores both the context and complexity that manifests in the meeting between the citizens everyday life and the public sector (Madsen et al. 2014). Digitalization of services can add to this complexity, but it can also create a basis for making sense of both individual and public value (Sklyar et al. 2019). As a municipal branch contemporary social work also illustrates the complexity of data-driven service arrangements within policy-driven organizations and networks. Even before the advent of digital technology, municipal social services were part of a vast information-ecology, tying together social security, healthcare, tax agencies, NGO's and the judicial system (Svensson 2019). And historically, local administrative branches have been reliant on the central city management in procurement and development of technical services and substructures. This means that the ownership of implementing, iterating and articulating the use of digital systems has been very much dominated by the city management IT departments, meaning that the practice of data not only was influenced by the commercial logics of the system developers, but also the municipal IT-department as an intermediary. 
In the case of both the cities Karlstad and Malmö, the context and the baseline for perceived success in cultivating democratic local data-culture was very much reliant on a data-literate leadership as well as the ability and time to explore data beyond the real and perceived ownership of data-driven systems and processes. Though the concept of data as both an individual and collective value-creator is not articulated, stakeholders in and around these processes voiced a need to situate themselves as experts in their own data. But as legal frameworks are changing and adapting around data ownership, the ability or mandate to explore data is attentively regulated. For example, on a European level, the General Data Protection Regulation in theory is meant to ensure the individual some form of ownership of one's data (EU 2016/679, n.d.). But given that many are unaccustomed to thinking about and conceptualizing data, the chance of malpractice in relations to GDPR discouraged practitioners within the social service fom advancing the current data-practice beyond the acting norms.

And just as democracy relies on the balance between individual and collective needs and interests, data-culture is a balance between organic growth and cultivation. So how to foster a policy logic for the public sector that maximizes data as an individual and communal resource? And how to do it in a way that takes into account socio-material context and a progressive approach to democracy? Drawing on the insights from Democracy Data, tying together the actualities on conflicting logics, the cognizance of data's latent risks and potentials as well as broadening the reasoning on democracy in the digital age, three proposals can be made.

\subsubsection{Proposals 1: Promote Holistic Data-Literacy}

It has been said that all data models are false, but that some are useful (Box 1976). Understanding what models are useful intrinsically means understanding the origin of data (Loukissas 2019). A holistic data-literacy, taking the alignment from context and accumulation of data to dissemination and decision making into account, hence is crucial for safeguarding individual and cultural wellbeing (Markham 2020).

Data-literacy, as understood by a conventional logic, is generally tied to doing data-work, such as modelling. However, the skillset to draw insight from data other than models and scale, and finding depth in insights, often requires going beyond the numeric realm, circumventing the view from nowhere (Haraway 1988). For example, in a given dataset representing a community, some citizens are bound not to be represented, especially if the data is based on digital interactions between citizens and government. As with any form of active participation, social capital impacts on the actual usage of data driven tools and service, especially in a government context (Naranjo-Zolotov et al. 2019). So, if a government agency is to iterate one of its digital services based only on existing user-data, then the improvement of the iteration will predominantly yield the existing user-base. The implication of such fallacy of dataliteracy, in an era of automation and AI, risks disenfranchising already marginalized groups within a community, as they are not represented in the accessible data. 
Here, it is important to promote and cultivate a data-literacy where you situate your practice in the socio-material context. Loukissas (2019) frames it as going from datasets to data-settings, exploring and examining the space for data accumulation together with data-stakeholders and policy makers. In practical terms, this means doing excursions, in-depth user-research or just meeting and interacting with the material-semiotics agents of a data dispositif. It might seem like a banal enterprise, but it inhabits a crucial aspect of the data-literacy skills; a critical view of causality. In public services, especially welfare services, data is being accumulated through the interaction between citizens and the service provider. You interact with your doctor, nurse or social service officer, where in an ideal circumstance, the both of you are trying to frame your needs consequently. In that data-setting, there are stratums of tacit information-language, power, gender, knowledge, bodies, etc. And the one appliance to translate this setting into digital data is the electronic journal system. A system that translates this interaction into a log (for QA and future decision making regarding you as an individual) and statistics (for knowledge and future decision making). If you as a data stakeholder, be it policy makers or analyst, don't situate yourself in that data-setting as part of your data-literacy ambition, there is a risk of losing the depth of insights needed to make relevant and justifiable decisions and policy.

\subsubsection{Proposals 2: Design Your Data-Driven Services as if Democracy Depended on It (Because It Does)}

Services matter in a democracy. If citizens don't believe that the services and utilities provided by their government is delivering value, they lose faith in the system (Peters 2010). And design matters in services. If a service design fails to capture the needs of its user, then there is no purpose of the service. And culture matters in design, as social structures arguably are crucial materials of holistic service design (Vink 2019).

Acknowledging that socio-materiality matters in the design process suggests that organizations can adapt a more all-encompassing understanding of the impact of its services (Akama 2015; Kimbell and Blomberg 2017). Citizens data, potentially, can be both an individual and collective good. And most often, the ability to use data right starts at accumulation. In service implementation, we have the rare ability to orchestrate accumulation of data in unique ways. But in order to maximize the use of data you need to design the space where digital data originates in a holistic way, drawing on the socio-material context, as well as contemplating where data as a resource could and should be used in aggregate forms. As the digital data accumulated today might last forever, and planning for perpetuity is no small matter, such designs need to be situated in agreement between both the citizen and the government. If data-driven service design is assuming that value is embedded in tangible outputs or exchanged between actors (Vargo and Lusch 2004), and we want to make it 
democratic and sustainable, it has to thoroughly acknowledge the complex systems into which the data is being propelled. This sober cognizance might be overwhelming. But instead of paralyzing data-practitioners and stakeholders, this realization can be used to elevate the role of design in both data-literacy and data-culture, and also to involve the citizens and their perspectives and realities in the discourse of one's data-culture.

Drawing from the research of Vink, there are a set of underlying assumptions in service design and development that is inhibiting certain cultures, organizations or networks from adopting a more situated understanding of design (Vink 2019). Working to shift these assumptions through practice and culture helps understand the gravity of designing a data-driven service, but also supposing a more holistic perspective on digital democracy. In practical terms this means adopting design practices and methodology among data practitioners and stakeholders, but also making sure that design of data-driven services and systems happens in dialogue not only between governmental branches, but also between citizens and government.

\subsubsection{Proposals 3: Conceptualize Data as Democratic Artifact}

Representation is central to the idea of democracy (Dahl and Shapiro 2015). If the structures and culture of a government do not allow for its citizens to be represented, through voting or public dialogue, then governments, in theory, lose its democratic legitimacy (Zittel and Fuchs 2006). So, as the role of data in public life is changing the government's work and as data represents citizens in a multitude of ways, how the government enacts the citizen needs reframing (Jaeger and Bertot 2010).

Conceptualizing future roles of technology always is done balancing between an utopian and dystopian rhetoric (Boyd and Crawford 2012). With the risk of slanting into both these realms it should however be emphasized, based on previous research and the insight from Democracy Data, that a data-driven public sector needs to view citizens data as both a democratic artifact and a conversation between citizens and the government. Data as enacting and representing the citizens. This notion of conceptualizing data as democratic artifact as well as a conversation between citizens and the government requires an established democratic foundation, including a holistic data-literacy and a design-oriented approach to value-creation.

Data as a democratic artifact means it manifests the citizen through a sort technique of representation. Just as a vote in a general election or a dialogue with elected officials tells us something about the position of the citizen and the community, so does data. If one draws from the actor-network-theory approach of translation, this could mean a process where a set of actors, human and non-human, become proxies for a multitude of other actors, where manifestations can be made based on articulating and linking identities in simplified or fixed forms (LaTour 1999; Law 1999). Data hence could represent one or many actors, and hence be both an individual and collective resource. And by avoiding the customer-oriented logics of commercial ontology, data-on a 
conceptual level — can be voiced as a source for constituting democracy as well as contributing to both individual and communal value-creation.

Dwelling on such conceptualizations, of course, for many public sector operatives would be an indulgence, given austerity measures and the sometimes harsh realities of contemporary public servants. However, in order to advance a data-culture that helps to articulate new and digitally relevant perspectives on democracy, decoupled from past and commercial logics, a new ontology is needed. Hence, appreciating data as both an individual and communal recourse, is but another step in the balance of advancing liberal democracy.

\section{References}

Akama Y (2015) Continuous re-configuring of invisible Social structures. In: Bruni EA, Parolin LL and Schubert C (eds) Designing technology, work, organizations and vice versa, Vernon Press, Malaga, pp 163-183

Bates J (2017) Data Cultures, Power and the City. Data and the City, 189-200. https://doi.org/10. 4324/9781315407388-14

Box GEP (1976) Science and statistics. J Am Stat Assoc 71(356):791-799

Boyd D, Crawford K (2012) Critical questions for big data. Inf, Commun \& Soc 15(5):662-679. https://doi.org/10.1080/1369118x.2012.678878

Chutimaskul W, Funilkul S (2004) The framework of E-democracy development. Lecture notes in computer science, pp 27-30. https://doi.org/10.1007/978-3-540-30078-6_5

Dahl RA, Shapiro I (2015) On democracy. Yale University Press. https://play.google.com/store/ books/details?id=5aYXCgAAQBAJ

Doneda D, Almeida VAF (2016) What is algorithm governance? IEEE Internet Comput 20(4):6063. https://doi.org/10.1109/mic.2016.79

Dyson E (1997) Release 2.0: a design for living in the digital age. Broadway Books. https://books. google.com/books/about/Release_2_0.html?hl=\&id=eFgy1GFW42YC

Ebbers WE, Marloes GMJ, van Deursen AJAM (2016) Impact of the digital divide on E-government: expanding from channel choice to Channel usage. GovMent Inf Q 33(4):685-692. https://doi. org/10.1016/j.giq.2016.08.007

EU 2016/679 (n.d.) Regulation (EU) 2016/679 of the European parliament and of the council of 27 April 2016 on the protection of natural persons with Regard to the processing of personal data and on the free movement of such data, and repealing directive 95/46/EC (General Data Protection Regulation) (Text with EEA Relevance). http://data.europa.eu/eli/reg/2016/679/oj

Fang Z (2002) E-government in digital era: concept, practice, and development. Int J Comput, Internet Manag 10 (January)

Grimsley M, Meehan A (2007) E-government information systems: evaluation-led design for public value and client trust. Eur J Inf Syst 16(2):134-148. https://doi.org/10.1057/palgrave.ejis.3000674

Hall PA, Taylor RCR (1996) Political science and the three new institutionalisms. Polit Stud 44(5):936-957. https://doi.org/10.1111/j.1467-9248.1996.tb00343.x

Haraway D (1988) Situated knowledges: the science question in feminism and the privilege of partial perspective. Fem Stud 14(3):575. https://doi.org/10.2307/3178066

Ho AT (2002) Reinventing local governments and the E-government initiative. Public Adm Rev 62(4):434-444. https://doi.org/10.1111/0033-3352.00197

Jaeger PT (2005) Deliberative democracy and the conceptual foundations of electronic government. GovMent Inf Q 22(4):702-719. https://doi.org/10.1016/j.giq.2006.01.012 
Jaeger PT, Bertot JC (2010) Designing, Implementing, and evaluating user-centered and citizencentered E-government. Citizens and E-Government, pp 1-19. https://doi.org/10.4018/978-161520-931-6.ch001

Keller S, Lancaster V, Shipp S (2017) Building capacity for data-driven governance: creating a new foundation for democracy. Stat Public Policy 4(1):1-11. https://doi.org/10.1080/2330443x.2017. 1374897

Kimbell L, Blomberg J (2017) The object of service design. Designing for Service. https://doi.org/ 10.5040/9781474250160.ch-006

Kitchin R (2015) The data revolution: big data, open data, data infrastructures and their consequences. Sage, London

Latour B (1999) On recalling ant. Sociol Rev 47(1_suppl):15-25

Layne K, Lee J (2001) Developing fully functional E-government: a four stage Model. GovMent Inf Q 18(2):122-136. https://doi.org/10.1016/s0740-624x(01)00066-1

Law J (1999) After ANT: Complexity, naming, and topology. In: Law J, Hassard J (eds) Actor network theory and after. Blackwell, Oxford, pp 1-14

Lindgren I, Madsen CØ, Hofmann S, Melin U (2019) Close encounters of the digital kind: a research agenda for the digitalization of public services. GovMent Inf Q 36(3):427-436. https://doi.org/ 10.1016/j.giq.2019.03.002

Loukissas YA (2019) All data are local. The MIT Press, Cambridge, MA. https://doi.org/10.7551/ mitpress/11543.001.0001

Madsen CØ, Bull Berger J, Phythian M (2014) The development in leading E-government articles 2001-2010: definitions, perspectives, scope, research philosophies, Methods and recommendations: an update of Heeks and Bailur. Lecture Notes in Computer Science, pp 17-34. https://doi. org/10.1007/978-3-662-44426-9_2

Markham AN (2020) Taking data literacy to the streets: critical pedagogy in the public sphere. Qual Inq 26(2):227-237. https://doi.org/10.1177/1077800419859024

Morgan I, Rao J (2003) Making routine customer experiences fun: some companies have discovered the competitive advantage of injecting the element of fun into traditionally neutral consumers environments. MIT Sloan Management Review, Gale Academic OneFile 45(1):93

Naranjo-Zolotov M, Oliveira T, Cruz-Jesus F, Martins J, Gonçalves R, Branco F, Xavier N (2019) Examining social capital and individual motivators to explain the adoption of online citizen participation. Futur Gener Comput Syst 92:302-311. https://doi.org/10.1016/j.future. 2018.09.044

Nelson DE, Bradford WH, Croyle RT (2009) Making data talk: the science and practice of translating public health research and surveillance findings to policy makers, the public, and the press. Oxford University Press. https://play.google.com/store/books/details?id=8CCWDwAAQBAJ

Nemitz P (2018) Constitutional democracy and technology in the age of artificial intelligence. Philos Trans R Soc, Math, Phys Eng Sci 376 (2133). https://doi.org/10.1098/rsta.2018.0089

Nielsen PA, Persson JS (2017) Useful business cases: value creation in IS projects. Eur J Inf Syst 26(1):66-83. https://doi.org/10.1057/s41303-016-0026-x

Norris P (2003) Preaching to the converted? Party Polit 9(1):21-45. https://doi.org/10.1177/135406 880391003

Penz O, Sauer B (2019) Governing affects. https://doi.org/10.4324/9781351212434

Peters BG (2010) Bureaucracy and democracy. Public Organ Rev 10(3):209-222. https://doi.org/ 10.1007/s11115-010-0133-4

Poullet Y (2009) Data protection legislation: what is at stake for our society and democracy? Comput Law \& Secur Rev 25(3):211-226. https://doi.org/10.1016/j.clsr.2009.03.008

Rheingold H (1994) The virtual community: finding connection in a computerized world. Harvill Secker, Minerva https://books.google.com/books/about/The_virtual_community.html?hl=\&id= A6e27y-PlkC

Sklyar A, Kowalkowski C, Tronvoll B, Sörhammar D (2019) Organizing for digital servitization: a service ecosystem perspective. J Bus Res, February. https://doi.org/10.1016/j.jbusres.2019. 02.012 
Svensson L (2019) Tekniken Är Den Enkla Biten: Om Att Implementera Digital Automatisering i Handläggningen Av Försörjningsstöd. Socialhögskolan, Lunds Universitet, Research reports in social works

Vargo SL, Archpru Akaka M, Vaughan CM (2017) Conceptualizing value: a service-ecosystem view. J Creat Value 3(2):117-124. https://doi.org/10.1177/2394964317732861

Vargo SL, Lusch RF (2004) Evolving to a new dominant logic for marketing. J Mark 68(1):1-17. https://doi.org/10.1509/jmkg.68.1.1.24036

Vink J (2019) In/Visible-conceptualizing service ecosystem design. PhD thesis, Karlastad University Studies, 2019:17

VINNOVA (2018) Democracy data-innovation management-for a data smart social services. https://www.vinnova.se/en/p/democracy-data-innovation-management-for-a-data-smart-soc ial-services/

West DM (2004) E-government and the transformation of service delivery and citizen attitudes. Public Adm Rev 64(1):15-27. https://doi.org/10.1111/j.1540-6210.2004.00343.x

Wynn-Williams CE (1931) The use of thyratrons for high speed automatic counting physical phenomena. Proceedings of the royal society of London. Series A, containing Papers of a mathematical and physical character 132(819):295-310. https://doi.org/10.1098/rspa.1931.0102

Zittel T, Fuchs D (2006) Participatory democracy and political participation: can participatory engineering bring citizens Back in? Routledge, Abingdon

Petter Falk is a service designer at RISE-Research Institutes of Sweden and a Ph.D student tied to political science and CTF-Center for Service Research at Karlstad University. In the intersection of political science, STS and critical studies Petter Falk is researching data as a democratic artifact in the public sector. Working closely with actors in both health care and social services, his research has explored the prerequisites and assumptions of data-culture through several research and innovation projects, both in Sweden and at an international level.

Open Access This chapter is licensed under the terms of the Creative Commons Attribution 4.0 International License (http://creativecommons.org/licenses/by/4.0/), which permits use, sharing, adaptation, distribution and reproduction in any medium or format, as long as you give appropriate credit to the original author(s) and the source, provide a link to the Creative Commons license and indicate if changes were made.

The images or other third party material in this chapter are included in the chapter's Creative Commons license, unless indicated otherwise in a credit line to the material. If material is not included in the chapter's Creative Commons license and your intended use is not permitted by statutory regulation or exceeds the permitted use, you will need to obtain permission directly from the copyright holder. 